\title{
MRI combined with PET-CT of different tracers to improve the accuracy of glioma diagnosis: a systematic review and meta-analysis
}

\author{
Yihan Yang ${ }^{1} \cdot$ Mike Z. $\mathrm{He}^{2} \cdot$ Tao $\mathrm{Li}^{1} \cdot{\text { Xuejun } \text { Yang }^{1}}^{1}$
}

Received: 18 January 2017 /Revised: 1 September 2017 / Accepted: 6 September 2017 /Published online: 16 September 2017

(C) The Author(s) 2017. This article is an open access publication

\begin{abstract}
Based on studies focusing on positron emission tomography (PET)-computed tomography (CT) combined with magnetic resonance imaging (MRI) in the diagnosis of glioma, we conducted a systematic review and meta-analysis evaluating the pros and cons and the accuracy of different examinations. PubMed and Cochrane Library were searched. The search was conducted until April 2017. Two reviewers independently conducted the literature search according to the criteria set initially. Based on the exclusion criteria, 15 articles are included in this study. Of all studies that used MRI examination, there are five involving 18F-fluorodeoxyglucosePET, five involving 11C-methionine-PET, five involving 18F-fluoro-ethyl-tyrosine-PET, and three involving 18Ffluorothymidine-PET. Due to the limitations such as lack of data, small sample size, and unrepresentative studies, we use a non-quantitative methodology. MRI examination can provide the anatomy information of glioma more clearly. PET-CT examinations based on tumor metabolism using different tracers have more advantages in determining the degree of glioma malignancy and boundaries. However, information provided by PET-CT of different tracers is not the same. With respect to the novel hybrid MRI/PET examination equipment proposed in recent years, the combination of MRI and PET-CT can definitively improve the diagnostic accuracy of glioma.
\end{abstract}

Keywords Glioma $\cdot$ MRI $\cdot$ PET-CT $\cdot$ Diagnostic accuracy

Xuejun Yang

ydenny@yahoo.com

1 Department of Neurosurgery, Tianjin Medical University General Hospital, No. 154 Anshan Road, Heping District, Tianjin 300052, China

2 Columbia University Mailman School of Public Health, New York, NY, USA

\section{Introduction}

Glioma is one type of intracranial space-occupying lesions with relatively high incidence $[51,55,80]$. In general, the management of glioma consists of imaging, surgery, and other postoperative treatment modalities [34, 38]. In terms of surgical options, including the selection of tumor resection or stereotactic biopsy, the determination of tumor margins during surgery, the necessity of postoperative radiation therapy, or even the decision of the radio-therapeutic modalities, preoperative imaging studies can provide crucial information [21]. As imaging technology continues to develop, a variety of different imaging methods are appearing, and a one imaging modality is becoming difficult to meet clinical needs. The concept of multi-modal imaging was therefore introduced, utilizing the information of two or more medical imaging modalities combined together to obtain more abundant and accurate information about a disease [6].

In actual clinical practice, conventional magnetic resonance imaging (MRI) examination is the first test for patients with suspected glioma. An MRI provides preliminary information about the tumor, including tumor location, size, and boundaries [25, 63, 77]. Information from a high-quality MRI image can be used in an operative setting and can provide valuable information to the surgeons. This information will improve the quality of surgery, closely related to the prognosis [79]. Furthermore, it can effectively assist the accurate grading of glioma [13]. Despite these advantages, diagnostic information provided by conventional MRI is preliminary and has a number of shortcomings, such as the lack of effectiveness under the absence of blood-brain barrier damage and difficulty in identifying abnormal imaging as tumor recurrence (tumor progression) or pseudo-progression [77].

In order to compensate the drawbacks of conventional MRI examination as mentioned above, positron emission tomography 
(PET)-(computed tomography) CT, based in tumor metabolic imaging, is used as a further test for suspected glioma [46]. PET-CT imaging is of vital importance of the functional imaging in glioma diagnosis. Combined with the anatomy information given by conventional MRI, PET-CT provides an important basis for more sensitive glioma treatment [60]. For example, when cases are difficult for MRI to evaluate, PET-CT can provide important notes for the diagnosis and imaging data to develop plans for the operation. In addition, it also provides indispensable information for patients' prognoses [7, 19, 30, 32, 36, 67, 85].

This paper summarizes research in the current literature that uses multi-modal images (conventional MRI and PETCT) for the diagnosis of glioma. It then systematically categorizes search results to obtain a comprehensive conclusion, providing valuable information for the diagnosis, treatment, and prognosis of different graded gliomas, concurrently serving as a foundation for future researchers interested in multimodal imaging of glioma diagnosis.

\section{Materials and methods}

Using PubMed and Cochrane Library, two reviewers independently conducted the literature search. We temporarily ignore the restrictions of language in the document retrieval process. Initial inclusion criteria included (1) researches on the diagnostic imaging of glioma and (2) imaging methods must include PET-CT regardless of the type of molecular reagent; at the same time, study must also involve the use of MRI imaging.

After the initial screening, reviewers detailedly reviewed articles from the initial screening and excluded articles using six exclusion criteria. Exclusion criteria included (1) sample size less than 10 ; (2) no comparison of two kinds of imaging methods; (3) research does not aim at improving the accuracy of glioma diagnosis, for example, research focused on the prognostic assessment; (4) study does not involve conventional MRI but advanced MRI, for example MRS and so on; (5) non-clinical studies, including animal level and cellular level research; and (6) non-English literature.

After the above screening, results obtained by the two reviewers were compared. Any disagreements were given to a third reviewer to determine whether the disputed article should be included in the systematic review (Fig. 1).

After the search in accordance with the above criteria, only a limited number of articles were found. Furthermore, samples of relevant studies are heterogeneous, and internal limitations cannot be ignored. Therefore, studies that merely aim at a particular glioma sub-category, such as research involving only high-grade gliomas, were not excluded. Studies that took place immediately after a specific situation, such as glioma recurrence after surgery and glioma assessment before radiotherapy, were also not excluded. Due to these limitations, the compiled data cannot be analyzed using traditional statistical methods. Instead, we use a non-quantitative methodology as our primary evaluation system, which compiles effective information from each article that is then further analyzed and discussed.

The two researchers extracted information from each of the documents independently. The information required includes the main topics of each study, the subjects studied, the approaches of data collection and integration, the conclusions, and the core information discussed in the results. After that, the researchers synthesize and contrast the extracted information.

\section{Results}

\section{Included studies}

After the initial screening, 12,336 articles were found in PubMed and 2498 articles were found in Cochrane Library. After reading the titles and abstracts of these articles, we retrieved a total 65 articles involving one or more of PET-CT examination combined with conventional MRI. Based on exclusion criteria, 15 articles are included in this study. According to the different PET-CT tracer, there are five studies involving 18F-fluorodeoxyglucose (FDG)-PET, five studies 11C-methionine (MET)-PET, five studies involving O-(2-[18F]fluoroethyl)-L-tyrosine (18F-FET)-PET, and three studies involving 3'-[18F]fluoro-3'-deoxythymidine (18FFLT)-PET (Table 1). Coincidentally, these four different PET-CT tracers are the four types frequently used clinically.

\section{Data of researches}

When analyzing the data from the researches (Table 2), we can see that, in general, although specificity of conventional MRI is relatively low, it has a relatively higher sensitivity. On the contrary, the sensitivity in the majority of PET-CT is not ideal, but the specificity is relatively high. When we make a comparison between low-grade gliomas and high-grade gliomas, we find that in terms of relatively low-grade gliomas, PET-CT for the diagnosis of high-grade gliomas indeed has an advantage, a point that coincides with our clinical experience. In terms of other articles and other data with heterogeneity, our analysis will be described in detail below.

\section{Discussion}

Glioma is the most common primary type of the nervous system tumors with its own unique heterogeneity. Depending on the characteristics of growth patterns and so on, glioma can be subclassed into WHO grade I, II, 
Fig. 1 Flow diagram of the study selection process

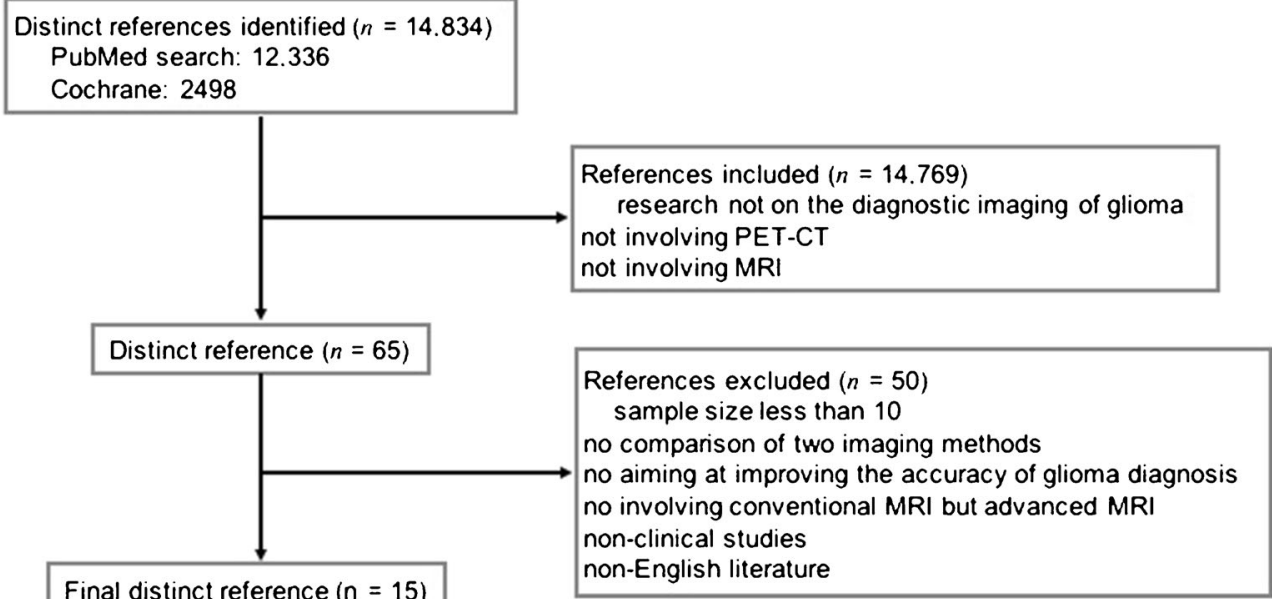

Final distinct reference $(n=15)$ Exception

Published before 2017/5
III, and IV. Overall, it can fall roughly into two categories, namely low-grade gliomas (LGG) and high-grade gliomas (HGG). From the perspective of growth pattern, low-grade gliomas grow relatively quietly, while high-grade gliomas grow actively, showing a kind of "aggressive" growth mode [53]. Furthermore, glioma is a typical heterogeneous tumor $[42,53]$. In the same tumor, there may be different grades of glioma components. This poses a greater problem before glioma surgery, including the development of postoperative treatment plans before radiotherapy. Thus, the use of a single imaging means inevitably cannot meet the needs of clinical practice. And glioma diagnosis must therefore be with the support of multi-modality image fusion technology.

Table 1 Included studies

\section{Conventional MRI}

As a better way of presenting intracranial structures than CT or other imaging scan, conventional MRI is used as the basic examination methods. It is the indispensable cornerstone of a variety of imaging means [61]. Published studies suggest that if surgery were done to remove $98 \%$ of disease displayed by enhanced MRI, the survival of glioblastomas would be benefited. In low-grade gliomas, if expansion resection was based on the T2-weighted MRI sequences, it is possible to predict overall survival $[39,65,72]$. However, conventional MRI judgment indeed has significant limitations when deciding glioma invasion and boundaries. For example, in anaplastic gliomas, MRI may show no contrast enhancement, and

\begin{tabular}{lllll}
\hline Authors and year & PET tracer & Subjects & Glioma type & $\begin{array}{l}\text { Patients received } \\
\text { therapy before }\end{array}$ \\
\hline Bšelohlávek et al., 2002 & 18F-FDG & 29 & LGG, HGG & + \\
Pauleit et al., 2005 & 18F-FET & 28 & WHO grade I IV & - \\
Walter et al., 2005 & 18F-FET & 45 & WHO grade I IV & + \\
Pirotte et al., 2006 & 11C-MET, 18F-FDG & 103 & LGG, HGG & - \\
Mira et al., 2004 & 11C-MET & 10 & GBM & - \\
Yamamoto et al., 2006 & 18F-FLT & 10 & GBM (recurrent) & + \\
Galldiks et al., 2010 & 11C-MET & 12 & Glioblastoma & + \\
Ewelt et al., 2011 & 18F-FET & 30 & WHO grade II IV & - \\
Santra et al., 2012 & 18F-FDG & 90 & WHO grade I IV & + \\
Arbizu et al., 2012 & 11C-MET & 23 & WHO grade II IV & + +- \\
Jansen et al., 2012 & 18F-FET & 127 & WHO grade I IV & - \\
Singhal et al., 2012 & 11C-MET, 18F-FDG & 102 & WHO grade I IV & NA \\
Nowosielski et al., 2014 & 18F-FET, 18F-FLT & 23 & WHO grade III, IV & - \\
Zhao et al., 2015 & 18F-FLT & 19 & WHO grade III, IV & + \\
Song et al., 2016 & 18F-FDG & 70 & NA & - \\
\hline
\end{tabular}

$N A=$ not available 
Table 2 Data of researches

\begin{tabular}{lllll}
\hline & & $\begin{array}{l}\text { Average } \\
\text { sensitivity/SD }\end{array}$ & $\begin{array}{l}\text { Average } \\
\text { specificity/SD }\end{array}$ & $\begin{array}{l}\text { Average } \\
\text { accuracy/SD }\end{array}$ \\
\hline MRI & Overall & $95.5 \% / 0.99 \%$ & $90.05 \% / 6.75 \%$ & $74.9 \% / 8.38 \%$ \\
& LGG & $67.57 \% / 42.38 \%$ & $26.2 \% / 7.56 \%$ & $63 \% / 4 \%$ \\
18 F-FDG-PET & HGG & $82.67 \% / 14.41 \%$ & $50.2 \% / 29.96 \%$ & $76.5 \% / 9.5 \%$ \\
& Overall & $66 \% / 3.5 \%$ & $90.05 \% / 6.75 \%$ & $70.9 \% / 6.44 \%$ \\
11 C-MET-PET & LGG & $65 \% / 25 \%$ & $100 \% / 0$ & $81 \% / 14 \%$ \\
18 F-FET-PET & HGG & $63.2 \% / 9.42 \%$ & $88.87 \% / 7.87 \%$ & $66.75 \% / 4.25 \%$ \\
& & NA/NA & NA/NA & $72 \% / \mathrm{NA}$ \\
& Overall & $92 \% / \mathrm{NA}$ & $81 \% / \mathrm{NA}$ & $\mathrm{NA} / \mathrm{NA}$ \\
18 F-FLT-PET & LGG & $66.35 \% / 12.55 \%$ & $11.8 \% / \mathrm{NA}$ & $\mathrm{NA} / \mathrm{NA}$ \\
\hline
\end{tabular}

$S D=$ standard deviation; $L G G=$ low-grade glioma; $H G G=$ high-grade glioma; $N A=$ not available

neoplastic cells often occur in regions outside the abnormal signal intensity. PET imaging may provide useful information in such situations $[56,64,75]$. So when (1) during the planning stages before glioma surgery or (2) postsurgery but before radiotherapy, PET-CT findings usually are added to improve the accuracy of tumor margin determination during the surgical removal process. 18F-FDG-PET and 11C-MET-PET are now commonly used in clinical PET examination [49]. In addition, 18F-FET-PET and 18F-FLT-PET are also applied. A combination of both MRI and PET-CT can provide more complete information, including the scope of the target tumor, thus providing a reliable basis for radiotherapy and neuronavigation surgery before treatment program development.

\section{F-FDG-PET versus conventional MRI}

The action principle of $18 \mathrm{~F}-\mathrm{FDG}-\mathrm{PET}$ is that $18 \mathrm{~F}-\mathrm{FDG}$ reagent can be uptaken by normal brain tissue and intracranial neoplastic tissue and be phosphorylated. But it cannot complete the normal glycolytic pathway, so it remains in cells. For intracranial tumor tissue, glucose utilization of tumor cells is relatively increased compared to normal brain tissue. At the same time, their metabolism also transforms from aerobic to anaerobic [45]. This behavior has a great relevance to the grade of gliomas. Thus, 18F-FDG-PET can be used as a means of judging the degree of malignancy. Furthermore, there is no uptake of $18 \mathrm{~F}-\mathrm{FDG}$ in the necrotic area, which can be effectively identified by 18 F-FDG-PET. However, 18F-FDG-PET also has its own limitations. First, the presence of normal gray matter will also show increased 18F-FDG uptake. In addition, with the exception of higher grade of glioma, other types of glioma remain iso-metabolic or hypometabolic compared to adjacent normal gray matter, which makes it difficult to distinguish between glioma tissue and normal brain tissue by using.
According to the literature we reviewed in this study, $18 \mathrm{~F}$ FDG PET-CT is superior in the diagnosis of gliomas to conventional MRI. Additionally, 18F-FDG PET-CT has some advantages in estimating glioma grade. In some cases of low-grade gliomas showing contrast-enhanced image in enhanced MRI, 18F-FDG-PET examinations will show low 18F-FDG uptake [71]. In cases suspected of tumor recurrence after treatment, including recurrent WHO grade II glioma conversion to the anaplastic glioma, early diagnosis and treatment are particularly critical for a good prognosis $[15,50]$. And in cases like this, due to necrosis after treatment or necrosis happening simultaneously with tumor progression leading to the destruction of the bloodbrain barrier (BBB) and the enhanced MRI diagnosing brain tumors, the diagnosis reliability of recurrence of enhanced MRI after treatment may be reduced [16, 59, 78]. Studies have shown that 18 F-FDG-PET for the detection of tumor recurrence has objectively high sensitivity and high accuracy. In addition, for patients having experienced surgery treatment doubted of glioma recurrence, abnormal signal in a conventional MRI may show a tumor lesion or may also be a reaction after treatment (such as radiation necrosis). At this time, 18F-FDG-PET can effectively distinguish which part is metabolic activity and which is tissue necrosis, which in turn provides information to infer the actual tumor size [66]. From another perspective, this shows that although 18F-FDG-PET has its advantages, conventional MRI examination is the essential foundation for inspection. Due to the relatively low 18F-FDG-PET's sensitivity, it is not as the first step in the diagnosis of glioma patients whether or not the tumor is a recurrence. For MRI results that found abnormalities, then the 18F-FDG-PET will have a certain advantage. In addition, various characteristics of 18F-FDG-PET make it possible for it to become a tool of judging glioma prognosis $[11,12]$. Another point worthy of note is that studies suggest there is no obvious link between PET lesion volume and survival in patients. The intensity of FDG uptake of tumor may instead be a more powerful predictor of survival [52]. 


\section{C-MET-PET versus MRI}

11C-MET-PET imaging is based on the needs of the cell protein synthesis precursors, which in turn is related to the proliferation of tissues and the degree of malignancy [9, 14, 49]. Since tumor tissue cells, compared with adjacent normal tissue cells, contain a richer metabolism-related protein, 11C-MET uptake will be richer. As a result, clear tumor boundaries against adjacent normal brain tissue will be formed [8, 33, 44, 76]. Furthermore, comparative 11C-MET-PET and MRI studies have shown that 11C-MET-PET can more effectively show the actual boundaries of the tumor (tumor range) [23, 37]. Regardless, 11CMET-PET also has its shortcomings, mainly having only a half-life of $20 \mathrm{~min}$, which is relatively short [61].

For enhanced MRI, especially in diagnosing glioblastoma multiforme (GBM), including recurrent GBM, the extension of tumor cells would exceed the scope of gadolinium developing. In many situations, 11C-MET-PET can form a tumor range larger than Gd does. The larger of the actual tumor diameter, the bigger the discrepancy between 11C-MET-PET and enhanced MRI there will be [43]. Existing studies have shown that (1) the tumor margin of 11C-MET-PET is larger than that of enhanced MRI and (2) there are scenarios where the conclusion of enhanced MRI is radiation necrosis but 11C-MET-PET concludes that there is a tumor. In both scenarios above, 11C-MET-PET provides the correct diagnoses upon verification by pathological examination. For most of the GBM, the target range of MRI is shown within the range of PET, so the tumor margin in the surgery is determined by $11 \mathrm{C}-\mathrm{MET}$-PET [2]. In the T2 sequence, T2-high area will be larger than the 11C-MET-PET area in the majority of cases. But there are some cases where tumor ranges of 11C-MET-PET displaying in some areas more than that of T2-high areas, indicating that the actual margin of GBM remains beyond T2-high area. T2-high area exceeding 11CMET-PET displaying range is considered as peritumoral edema. In low-grade gliomas, the tumor range depicted by $\mathrm{T} 2$-weighted MRI is larger than the display range of 11C-MET-PET. When selective biopsies were done in these areas, no tumor tissue in these regions or less aggressive lesions were found. Therefore, in cases when T2-weighted MRI is difficult to determine the tumor border, 11C-MET-PET can be used as tool to determine the boundary of tumor for tumor resection [2, 24, 35, 48, 70, 73]. 11C-MET-PET is a powerful means of detecting low-grade gliomas, which may provide useful information for surgery and stereotactic biopsy planning.

\section{F-FET-PET versus MRI}

In 18F-FET-PET, tumor tissue and endothelial cell specifically uptake the tracer, and the uptake volume depends on the number of cell density and tumor microvessel density [74]. Some factors can increase BBB damage, which also leads to increased uptake of amino acid tracers [18, 26, 40, 57]. 18F-
FET can be produced in mass (18F-labeled amino acid) and it can meet daily clinical needs [83]. In human plasma, 18F-FET will not decrease because of metabolism, and it has good stability in the tumor tissue inside the brain and brain tissue itself within 15 min after injection. It is possible for $18 \mathrm{~F}-\mathrm{FET}$ PET in clinical practice to provide important information of brain lesion discovering, prognosis assessment, and tumor grading [18-20, 54, 58, 81].

Literature from our review shows that 18F-FET-PET can identify high-grade gliomas that enhanced MR imaging is unable to detect. 18F-FET-PET in conjunction with conventional MRI is often able to achieve higher diagnostic accuracy for glioma diagnosis, while MRI alone is difficult to achieve the same result [47]. Interestingly, Nowosielski et al.'s study showed that a considerable portion of $18 \mathrm{~F}$-FET uptake range greater than the range of enhancement of MRI displaying, and the uptake of 18F-FET has only a moderate correlation with contrast volume in enhanced MRI. On the other hand, Christian Ewelt et al. found that 18F-FET uptake always falls within the scope of MRI abnormalities' signal range in WHO grade II to grade IV gliomas. More research should be carried out on this topic in the future. In cases suspected low-grade gliomas after MRI scan, the positive 18FFET-PET tends to have higher possibilities of indicating tumor correctly. Note that if it revealed a kinetic but not conventional analysis of 18F-FET uptake after 18F-FET-PET scan, the tumor may be high-grade gliomas [29]. Experiments show that if the result of $18 \mathrm{~F}$-FET-PET is negative, then the possibility come to a diagnosis of malignant glioma is not high [17].

\section{F-FLT-PET versus MRI}

In the 18F-FLT-PET imaging process, 18F-FLT move through the cell membrane into the cell by facilitated diffusion. It is then phosphorylated, assisted by TK1, to present intracellular trapping. During DNA synthesis, TK1 increased tenfold. In the same time, due to the more active proliferation behavior, glioma cells uptake $18 \mathrm{~F}-\mathrm{FLT}$ and form an image $[5,22,68]$. In addition, 18FFLT uptake needs the BBB as basis $[28,69]$. So 18 F-FLT-PET imaging is mainly based on cell proliferation, namely TK1 activity, and BBB permeability. In enhanced MRI, the imaging developing via gadolinium-DTPA (diethylenetriamine pentaacetic acid) (Gd-DTPA) is achieved by going through the $\mathrm{BBB}$, which is associated with tumor vascularization and proliferation. Given the completeness of the BBB, when high-grade glioma patients have no significant 18F-FLT uptake, simultaneously, there would be no contrast enhancement in MRI [47]. Previous studies have shown that the reason why 18F-FLT uptake of normal brain tissue is not significant is the intactness of the BBB and lower proliferative activity, which in turn also confirmed the principle of glioma tissue uptaking 18F-FLT and imaging. 18F-FLT-PET has obvious advantages in actual clinical practice, which is the formation of a clear boundary between the glioma tissues and adjacent normal brain tissues. Of course, the 
destruction of the BBB has become a limitation of 18F-FLTPET, in particular limiting its application in the diagnosis of low-grade gliomas [5].

Although 18F-FLT-PET imaging is based on the destruction of the BBB, when 18F-FLT-PET and conventional MRI were contrasted, previous study found that 18F-FLT-PET can reveal the extent of tumor that cannot be detected by enhanced MRI [28]. Zhao et al.'s study mentioned that the tumor boundary demonstrated by 18 F-FLT-PET is not limited to which enhanced MRI showed. In most cases, it exceeds the scope of MRI can display. Furthermore, the expanding range of $18 \mathrm{~F}$ FLT uptake does not uniformly surround which MRI displays. Interestingly, in Yamamoto et al.'s Study, 18F-FLT accumulation volume is closely related to the enhanced amount of GdDTPA in enhancement MRI. Total tumor volume showed by 18F-FLT-PET is similar to that of enhanced MRI displays. However, the exact tumor boundaries showed by these two methods are not the same [84]. For postoperative residual tumor imaging of malignant glioma patients having received surgical treatment, 18F-FLT-PET does not necessarily show abnormalities consistent with postoperative MRI [86]. The real postoperative residual tumors may be undervalued or overvalued by MRI [82]. When cases having undergone resection of glioma receive conventional MRI and 18F-FLTPET scan, if the cavity margin MRI displayed is larger than 18F-FLT-PET did, it might mean that the scope beyond is postoperative reaction and not the real residual tumor border.

\section{Various types of PET-CT in combination with conventional MRI}

PET-CT scan of different tracer and conventional MRI each have their advantages and disadvantages. 18F-FDG-PET and 11C-MET-PET are currently the more widely used tests. The former has a great advantage for the identification of nonglioma tissue forming a good contrast with the non- $18 \mathrm{~F}-$ FDG-uptake necrotic tissue, while the latter can make the tumor and peritumoral tissues well distinguished in the image formed by PET-CT examination which will form relatively true and accurate tumor boundary. Furthermore, there is value for glioma grade prediction. Studies have shown that highgrade gliomas have a significantly higher 11C-MET, 18FFDG uptake than low-grade gliomas. In evaluating the prognosis of glioma, 18F-FDG-PET has its prognostic value for glioma patients with a certain presence of contrast enhancement in enhanced MRI. But with the absence of contrast enhancement or in low-grade glioma patients, 11C-MET-PET can predict survival. In our review of relevant studies, 11CMET-PET has a greater advantage than 18F-FDG-PET and MRI for low-grade glioma survival prediction. Moreover, $11 \mathrm{C}-$ MET-PET is not only stronger than conventional imaging in providing prognostic information, but also stronger than the histopathology. It is possible that tumor necrosis and the presence of BBB damage can lead to high uptake of 11CMET. Therefore, 11C-MET-PET for high-grade gliomas provides no prognostic value. However, both methods have their own limitations. For example, due to normal tissue 18F-FDG uptake, 18F-FDG-PET fails to form the boundary between tumor tissue and normal brain tissue. The shorter half-life of $11 \mathrm{C}-\mathrm{MET}$ limits its usage. Because of these limitations, 18FFET-PET and 18F-FLT-PET emerged as more popular candidates. Comparing the two tests in the same patients, 18F-FETPET can detect a larger tumor range than 18F-FLT-PET, indicating 18F-FET PET-CT can reflect the actual tumor boundary better. Furthermore, studies show that 18F-FET-PET has a higher detection rate of high-grade gliomas compared to 18F-FLT-PET. If the result of 18F-FET-PET is negative, then the possibility of coming to a diagnosis of malignant glioma is not high. 18F-FLT-PET imaging needs to be based on the BBB damage. Therefore, although some high-grade gliomas have a high proliferation index, 18F-FLT-PET probably remains of no use. Nevertheless, the boundaries shown by PET-CT remain the general boundaries of the tumor. For gliomas, especially malignant gliomas, there may be a single tumor cell or a plurality of tumor cells invading distantly. In this respect, it is difficult for the PET-CT to form an image. In terms of safety issues, there is no exact experimental evidence showing that PET-CT shares a long-term risk [3].

The notion that the application of CT and MRI can be used for distinguishing low-grade glioma tumor tissue from peritumoral normal brain tissue has already been recognized. With the continuous clinical practice, including enhancement MRI, conventional MRI scan alone has its limitations in identifying glioma as well as glioma grading. Biopsy or surgical resection decisions based solely on MRI information is unreliable. There may be false positive judgment of tumor grading and tumor invasion range, and this is explicitly presented in each study. For example, in T2-weighted FLAIR sequences exhibiting enhanced signal cases, only about half of the cases proved to be the actual tumor tissue after biopsy. There are also a considerable portion of patients with suspected glioma not presenting MRI contrast enhancement, or lack contrastenhanced MRI at an early stage. However, the final pathologic diagnosis shows high-grade gliomas. Furthermore, for the follow-up evaluation of glioma patients having undergone multiple treatment, conventional MRI alone is not enough. At the same time, conventional MRI does have its indispensable role. Various studies have shown that conventional MRI combined with PET-CT is more valuable in judging tumor tissue and peritumoral brain tissue.

In clinical practice, advanced MRI is also valuable for the diagnosis of gliomas by providing more information on gliomas that is not available from conventional MRI. Examples of some available techniques include perfusion-weighted imaging (PWI), diffusion-weighted imaging (DWI), proton magnetic resonance spectroscopy (MRS), and diffusion tensor imaging 
(DTI) [41]. For instance, in PWI, the relative cerebral blood volume (rCBV) can be used to show malignant transformation of gliomas earlier than the emergence of new enhancement spot in enhanced MRI [1]. rCBV can be used to accurately differentiate grade II gliomas and grade III gliomas [87]. Higher-order diffusion techniques such as diffusion kurtosis imaging, a DWIrelated new technology, can describe the changes in microstructure [31]. Preliminary studies suggest that this technique has a certain prospect in the differential diagnosis of brain tumors [31]. MRS can provide metabolic information of gliomas similar to that of PET-CTs or information complementary to PETCTs. Based on the above, there are many existing studies that compare advanced MRI and PET and explore the significance of these two imaging methods combined in diagnosing glioma. In terms of DWI and PET-CT comparisons, studies have shown that DWI has limitations in diagnosing LGG. Compared with DWI, the diagnostic usage of 18F-FET-PET on LGG is irreplaceable [62]. In general, the accuracy of $1 \mathrm{H}$ MRS in diagnosing glioma progression was lower than that of $18 \mathrm{~F}-\mathrm{FDG}-\mathrm{PET}$ [27]. 1H MRS has a higher diagnostic accuracy for LGG, and 18F-FDG-PET has a higher accuracy in the diagnosis of HGG $[1,27]$. However, there are studies showing that MRS is valuable for the diagnosis of HGG [41]. This is a topic that is worth investigating in future research. On the other hand, advanced MRI and PET-CT can provide different information about gliomas. The information can enrich the understanding of gliomas before treatment. A study by Collet et al. suggests that advanced MRI and 18F-FLT PET-CT can improve the diagnostic efficiency of gliomas [10]. More prospective, large-sample experiments should be conducted in the future to explore methods to improve the accuracy of preoperative diagnosis of glioma using a combination of advanced MRI and PET-CT.

For neurosurgeons, it is important to have a precise selection of imaging examinations. For the patients admitted initially, conventional MRI is essential. It can provide anatomical information about glioma, which is the cornerstone of surgical treatment. PET-CT is of great importance for patients who have undergone MRI scan and been suspected suffering from gliomas, especially unclear-grade or high-grade gliomas. When concerning about the four different tracers of PET-CT, 18FFDG PET-CT and 11C-MET PET-CT are two basic types of PET-CT scans. 18F-FDG PET-CT can show necrosis in tumor tissue. According to the different biological activity of gliomas, 11C-MET PET-CT can reflect the boundary of the tumor more closed to the biological situation, providing information for the glioma total resection. Both 18F-FDG PET-CT and 11C-MET PET-CT can give information on the grade prediction of gliomas based on the tracer uptake. In general, both 18F-FET PETCT and 18F-FLT PET-CT are able to provide information for glioma border determinations. With the technique of multimodality image fusion, PET-CT and MRI results can be fused to gain much more accurate information on the boundaries of gliomas, which can be utilized in the surgery (Table 3).

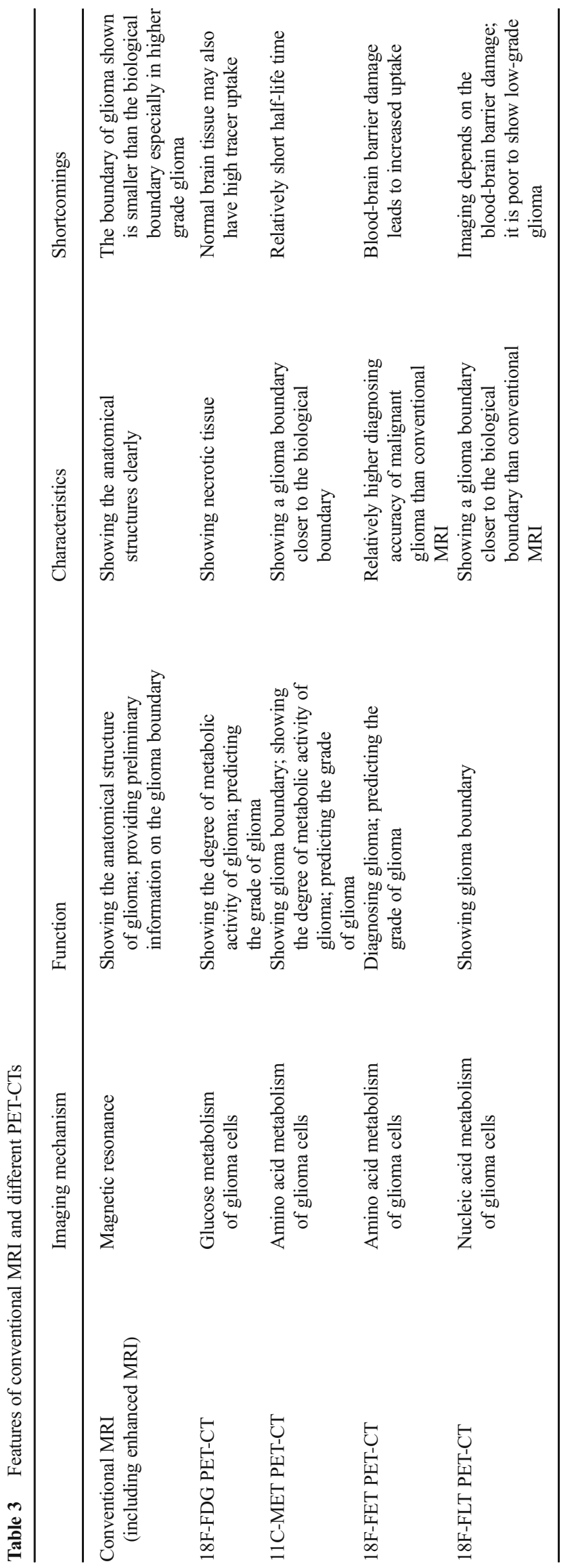




\section{Conclusion}

Based on metabolic imaging, various PET-CTs showed different strengths but also different limitations. Overall, the studies, in varying degrees, were indicative of PET-CT to show tumor boundaries better than conventional MRI. But compared to PET-CT, conventional MRI can more clearly show the anatomical structure, which is a function cannot be replaced by any variety of PET-CT. Therefore, PET-CT and MRI are often combined to achieve high accuracy that any single examination method fails to achieve. In recent years, the concept of hybrid PET/MRI scanner is presented, fitting the conclusion of this systematic review and reflecting the new trend of glioma diagnosis. It can efficiently provide more comprehensive, high-resolution information for glioma preoperative planning, intraoperative neuro-navigation, and even postoperative treatments, such as radiotherapy [4].

Funding Funding is based on a research grant from the Chinese AntiCancer Association Neuro-Oncology Research Project, and applicable grant numbers is CSNO2014MSD01.

\section{Compliance with ethical standards}

Conflict of interest The authors declare that they have no conflicts of interest.

Ethical approval Because this study is a systematic review and does not involve original data, ethical approval was not required.

Informed consent Because this study is a systematic review and does not involve original data, informed consent is not applicable.

Open Access This article is distributed under the terms of the Creative Commons Attribution 4.0 International License (http:// creativecommons.org/licenses/by/4.0/), which permits unrestricted use, distribution, and reproduction in any medium, provided you give appropriate credit to the original author(s) and the source, provide a link to the Creative Commons license, and indicate if changes were made.

\section{References}

1. Ahmed R, Oborski MJ, Hwang M, Lieberman FS, Mountz JM (2014) Malignant gliomas: current perspectives in diagnosis, treatment, and early response assessment using advanced quantitative imaging methods. Cancer Manag Res 6:149-170. https://doi.org/ 10.2147/CMAR.S54726

2. Arbizu J, Tejada S, Marti-Climent JM, Diez-Valle R, Prieto E, Quincoces G, Vigil C, Idoate MA, Zubieta JL, Peñuelas I, Richter JA (2012) Quantitative volumetric analysis of gliomas with sequential MRI and 11C-methionine PET assessment: patterns of integration in therapy planning. Eur J Nucl Med Mol Imaging 39:771781. https://doi.org/10.1007/s00259-011-2049-9

3. Bach-Gansmo T, Nanni C, Nieh PT, Zanoni L, Bogsrud TV, Sletten H, Korsan K, Kieboom J, Tade F, Odewole O, Chau A, Ward P, Goodman MM, Fanti S, Schuster DM, Willoch F (2016) Multi-site experience of the safety, detection rate and diagnostic performance of fluciclovine (18F) PET/CT imaging in the staging of biochemically recurrent prostate cancer. J Urol. https://doi.org/10. 1016/j.juro.2016.09.117

4. Bailey DL, Barthel H, Beyer T, Boellaard R, Gückel B, Hellwig D, Herzog H, Pichler BJ, Quick HH, Sabri O, Scheffler K, Schlemmer HP, Schwenzer NF, Wehrl HF (2013) Summary report of the first international workshop on PET/MR imaging, March 19-23, 2012, Tübingen, Germany. Mol Imaging Biol 15:361-371. https://doi. org/10.1007/s11307-013-0623-1

5. Barwick T, Bencherif B, Mountz JM, Avril N (2009) Molecular PET and PET/CT imaging of tumour cell proliferation using F-18 fluoro-L-thymidine: a comprehensive evaluation. Nucl Med Commun 30:908-917. https://doi.org/10.1097/MNM. 0b013e32832ee93b

6. Belliveau J-G, Bauman G, Macdonald DR (2016) Detecting tumor progression in glioma: current standards and new techniques. Expert Rev Anticancer Ther 1-12. https://doi.org/10.1080/ 14737140.2016.1240621

7. Belohlavek O, Fencl P, Majovsky M, Jaruskova M, Benes V (2014) FLT-PET in previously untreated patients with low-grade glioma can predict their overall survival. Nucl Med Rev 17:7-12. https:// doi.org/10.5603/NMR.2014.0003

8. Bergström M, Collins VP, Ehrin E, Ericson K, Eriksson L, Greitz T, Halldin C, von Holst H, Långström B, Lilja A (1983) Discrepancies in brain tumor extent as shown by computed tomography and positron emission tomography using [68Ga]EDTA, [11C]glucose, and [11C]methionine. J Comput Assist Tomogr 7:1062-1066

9. Bustany P, Chatel M, Derlon JM, Darcel F, Sgouropoulos P, Soussaline F, Syrota A (1986) Brain tumor protein synthesis and histological grades: a study by positron emission tomography (PET) with C11-L-methionine. J Neuro-Oncol 3:397-404

10. Collet S, Valable S, Constans JM, Lechapt-Zalcman E, Roussel S, Delcroix N, Abbas A, Ibazizene M, Bernaudin M, Barré L, Derlon JM, Guillamo JS (2015) $\left[{ }^{18} \mathrm{~F}\right]$-fluoro-l-thymidine PET and advanced MRI for preoperative grading of gliomas. NeuroImage Clin 8:448-454. https://doi.org/10.1016/j.nicl.2015.05.012

11. De Witte O, Levivier M, Violon P, Salmon I, Damhaut P, Wikler D Jr, Hildebrand J, Brotchi J, Goldman S (1996) Prognostic value of positron emission tomography with [18F]fluoro-2-deoxy-D-glucose in the low-grade glioma. Neurosurgery 39:470-476

12. De Witte O, Goldberg I, Wikler D, Rorive S, Damhaut P, Monclus M, Salmon I, Brotchi J, Goldman S (2001) Positron emission tomography with injection of methionine as a prognostic factor in glioma. J Neurosurg 95:746-750. https://doi.org/10.3171/jns. 2001.95.5.0746

13. Dean BL, Drayer BP, Bird CR, Flom RA, Hodak JA, Coons SW, Carey RG (1990) Gliomas: classification with MR imaging. Radiology 174:411-415. https://doi.org/10.1148/radiology.174.2. 2153310

14. Derlon JM, Bourdet C, Bustany P, Chatel M, Theron J, Darcel F, Syrota A (1989) [11C]L-methionine uptake in gliomas. Neurosurgery 25:720-728

15. Devaux BC, O'Fallon JR, Kelly PJ (1993) Resection, biopsy, and survival in malignant glial neoplasms. A retrospective study of clinical parameters, therapy, and outcome. J Neurosurg 78:767775. https://doi.org/10.3171/jns.1993.78.5.0767

16. Dooms GC, Hecht S, Brant-Zawadzki M, Berthiaume Y, Norman D, Newton TH (1986) Brain radiation lesions: MR imaging. Radiology 158:149-155. https://doi.org/10.1148/radiology.158.1. 3940373

17. Ewelt C, Floeth FW, Felsberg J, Steiger HJ, Sabel M, Langen KJ, Stoffels G, Stummer W (2011) Finding the anaplastic focus in diffuse gliomas: the value of Gd-DTPA enhanced MRI, FET-PET, and intraoperative, ALA-derived tissue fluorescence. Clin Neurol Neurosurg 113:541-547. https://doi.org/10.1016/j.clineuro.2011. 03.008 
18. Floeth FW, Pauleit D, Sabel M, Reifenberger G, Stoffels G, Stummer W, Rommel F, Hamacher K, Langen K-J (2006) 18FFET PET differentiation of ring-enhancing brain lesions. J Nucl Med 47:776-782

19. Floeth FW, Pauleit D, Sabel M, Stoffels G, Reifenberger G, Riemenschneider MJ, Jansen P, Coenen HH, Steiger H-J, Langen K-J (2007) Prognostic value of O-(2-18F-fluoroethyl)-L-tyrosine PET and MRI in low-grade glioma. J Nucl Med 48:519-527. https://doi.org/10.2967/jnumed.106.037895

20. Floeth FW, Sabel M, Stoffels G, Pauleit D, Hamacher K, Steiger HJ, Langen KJ (2008) Prognostic value of (18)F-fluoroethyl-L-tyrosine PET and MRI in small nonspecific incidental brain lesions. J Nucl Med 49:730-737. https://doi.org/10.2967/jnumed.107. 050005

21. Fouke SJ, Benzinger T, Gibson D, Ryken TC, Kalkanis SN, Olson JJ (2015) The role of imaging in the management of adults with diffuse low grade glioma: a systematic review and evidence-based clinical practice guideline. J Neuro-Oncol 125:457-479. https://doi. org/10.1007/s11060-015-1908-9

22. Grierson JR, Shields AF (2000) Radiosynthesis of 3J-deoxy-3J[18F]fluorothymidine: $[18 \mathrm{~F}]$ FLT for imaging of cellular proliferation in vivo. Science (80- ) 27:143-156

23. Grosu AL, Weber WA, Riedel E, Jeremic B, Nieder C, Franz M, Gumprecht H, Jaeger R, Schwaiger M, Molls M (2005) L-(methyl11C) methionine positron emission tomography for target delineation in resected high-grade gliomas before radiotherapy. Int J Radiat Oncol Biol Phys 63:64-74. https://doi.org/10.1016/j.ijrobp.2005. 01.045

24. Herholz K, Bauer B, Hölzer T, Thiel A, Wienhard K, Heiss W-D, Weber-Luxenburge G, Mendoza G, Ernestus R-I, Voges J, Schroder R (1998) C-methionine PET for differential diagnosis of low-grade gliomas. Neurology 50:1316-1322. https://doi.org/10.1212/WNL. 50.5.1316

25. Huk W, Gademann G (1984) Magnetic resonance imaging (MRI): method and early clinical experiences in diseases of the central nervous system. Neurosurg Rev 7:259-280

26. Hutterer M, Nowosielski M, Putzer D, Jansen NL, Seiz M, Schocke M, McCoy M, Göbel G, La Fougère C, Virgolini IJ, Trinka E, Jacobs AH, Stockhammer G (2013) [18F]-fluoro-ethyl-1-tyrosine PET: a valuable diagnostic tool in neuro-oncology, but not all that glitters is glioma. Neuro-Oncology 15:341-351. https://doi.org/10. 1093/neuonc/nos300

27. Imani F, Boada FE, Lieberman FS, Davis DK, Deeb EL, Mountz JM (2012) Comparison of proton magnetic resonance spectroscopy with fluorine-18 2-fluoro-deoxyglucose positron emission tomography for assessment of brain tumor progression. J Neuroimaging 22:184-190. https://doi.org/10.1111/j.1552-6569.2010.00561.x

28. Jacobs AH, Thomas A, Kracht LW, Li H, Dittmar C, Garlip G, Galldiks N, Klein JC, Sobesky J, Hilker R, Vollmar S, Herholz K, Wienhard K, Heiss W-D (2005) 18F-fluoro-L-thymidine and 11Cmethylmethionine as markers of increased transport and proliferation in brain tumors. J Nucl Med 46:1948-1958

29. Jansen NL, Graute V, Armbruster L, Suchorska B, Lutz J, Eigenbrod S, Cumming P, Bartenstein P, Tonn JC, Kreth FW, La Fougère $C$ (2012) MRI-suspected low-grade glioma: is there a need to perform dynamic FET PET? Eur J Nucl Med Mol Imaging 39: 1021-1029. https://doi.org/10.1007/s00259-012-2109-9

30. Jansen NL, Suchorska B, Wenter V, Schmid-Tannwald C, Todica A, Eigenbrod S, Niyazi M, Tonn JC, Bartenstein P, Kreth FW, la Fougere C (2015) Prognostic significance of dynamic 18F-FET PET in newly diagnosed astrocytic high-grade glioma. J Nucl Med 56:9-15. https://doi.org/10.2967/jnumed.114.144675

31. Jensen JH, Helpern JA (2010) MRI quantification of non-Gaussian water diffusion by kurtosis analysis. NMR Biomed 23:698-710. https://doi.org/10.1002/nbm.1518
32. Jung T-Y, Min J-J, Bom H-S, Jung S, Kim I-Y, Lim S-H, Kim D-Y, Kwon SY (2016) Prognostic value of post-treatment metabolic tumor volume from 11C-methionine PET/CT in recurrent malignant glioma. Neurosurg Rev. https://doi.org/10.1007/s10143-016-0748-1

33. Kaschten B, Stevenaert A, Sadzot B, Deprez M, Degueldre C, Del Fiore G, Luxen A, Reznik M (1998) Preoperative evaluation of 54 gliomas by PET with fluorine-18-fluorodeoxyglucose and/or carbon-11-methionine. J Nucl Med 39:778-785

34. Khan M, Sharma A, Pitz M, Loewen S, Quon H, Poulin A, Essig M (2016) High-grade glioma management and response assessmentrecent advances and current challenges. Curr Oncol 23:383-391. https://doi.org/10.3747/co.23.3082

35. Kinoshita M, Hashimoto N, Goto T, Yanagisawa T, Okita Y, Kagawa N, Kishima H, Tanaka H, Fujita N, Shimosegawa E, Hatazawa J, Yoshimine T (2009) Use of fractional anisotropy for determination of the cut-off value in 11C-methionine positron emission tomography for glioma. NeuroImage 45:312-318. https://doi. org/10.1016/j.neuroimage.2008.11.034

36. Kobayashi K, Hirata K, Yamaguchi S, Manabe O, Terasaka S, Kobayashi H, Shiga T, Hattori N, Tanaka S, Kuge Y, Tamaki N (2015) Prognostic value of volume-based measurements on 11Cmethionine PET in glioma patients. Eur J Nucl Med Mol Imaging 42:1071-1080. https://doi.org/10.1007/s00259-015-3046-1

37. Kracht LW, Miletic H, Busch S, Jacobs AH, Voges J, Hoevels M, Klein JC, Herholz K, Heiss WD (2004) Delineation of brain tumor extent with [11C] 1-methionine positron emission tomography. Clin Cancer Res 10:7163

38. Kumthekar P, Raizer J, Singh S (2015) Low-grade glioma. Cancer Treat Res 163:75-87

39. Lacroix M, Abi-Said D, Fourney DR, Gokaslan ZL, Shi W, DeMonte F, Lang FF, McCutcheon IE, Hassenbusch SJ, Holland E, Hess K, Michael C, Miller D, Sawaya R (2001) A multivariate analysis of 416 patients with glioblastoma multiforme: prognosis, extent of resection, and survival. J Neurosurg 95:190-198. https:// doi.org/10.3171/jns.2001.95.2.0190

40. Langen KJ, Hamacher K, Weckesser M, Floeth F, Stoffels G, Bauer D, Coenen HH, Pauleit D (2006) O-(2-[18F]fluoroethyl)-1-tyrosine: uptake mechanisms and clinical applications. Nucl Med Biol 33: 287-294. https://doi.org/10.1016/j.nucmedbio.2006.01.002

41. Löbel U, Ellison DW, Shulkin BL, Patay Z (2011) Infiltrative cerebellar ganglioglioma: conventional and advanced MRI, proton MR spectroscopic, and FDG PET findings in an 18- month-old child. Clin Radiol 66:194-201. https://doi.org/10.1016/j.crad. 2010.10.005

42. Lupo JM, Nelson SJ (2014) Advanced magnetic resonance imaging methods for planning and monitoring radiation therapy in patients with high-grade glioma. Semin Radiat Oncol 24:248-258. https:// doi.org/10.1016/j.semradonc.2014.06.008

43. Miwa K, Shinoda J, Yano H, Okumura A, Iwama T, Nakashima T, Sakai N (2004) Discrepancy between lesion distributions on methionine PET and MR images in patients with glioblastoma multiforme: insight from a PET and MR fusion image study. $\mathrm{J}$ Neurol Neurosurg Psychiatry 75:1457-1462. https://doi.org/10. 1136/jnnp.2003.028480

44. Mosskin M, Ericson K, Hindmarsh T, Von Holst H, Collins VP, Bergstrom M, Eriksson L, Johnstrom P (1989) Positron emission tomography compared with magnetic resonance imaging and computed tomography in supratentorial gliomas using multiple stereotactic biopsies as reference. Acta Radiol 30:225-232. https://doi. org/10.1177/028418518903000301

45. Muzi M, Freeman SD, Burrows RC, Wiseman RW, Link JM, Krohn KA, Graham MM, Spence AM (2001) Kinetic characterization of hexokinase isoenzymes from glioma cells: implications for FDG imaging of human brain tumors. Nucl Med Biol 28:107-116. https://doi.org/10.1016/S0969-8051(00)00201-8 
46. Nihashi T, Dahabreh IJ, Terasawa T (2013) PET in the clinical management of glioma: evidence map. Am J Roentgenol 200: 654-660. https://doi.org/10.2214/AJR.12.9168

47. Nowosielski M, DiFranco MD, Putzer D, Seiz M, Recheis W, Jacobs AH, Stockhammer G, Hutterer M (2014) An intraindividual comparison of MRI, [18F]-FET and [ 18F]-FLT PET in patients with high-grade gliomas. PLoS One. https://doi.org/10. 1371/journal.pone.0095830

48. Nuutinen J, Sonninen P, Lehikoinen P, Sutinen E, Valavaara R, Eronen E, Norrgård S, Kulmala J, Teräs M, Minn H (2000) Radiotherapy treatment planning and long-term follow-up with $[(11) C]$ methionine PET in patients with low-grade astrocytoma. Int J Radiat Oncol Biol Phys 48:43-52

49. Ogawa T, Shishido F, Kanno I, Inugami A, Fujita H, Murakami M, Shimosegawa E, Ito H, Hatazawa J, Okudera T (1993) Cerebral glioma: evaluation with methionine PET. Radiology 186:45-53

50. Okamoto Y, Di Patre PL, Burkhard C, Horstmann S, Jourde B, Fahey M, Schüler D, Probst-Hensch NM, Yasargil MG, Yonekawa Y, Lütolf UM, Kleihues P, Ohgaki H (2004) Population-based study on incidence, survival rates, and genetic alterations of low-grade diffuse astrocytomas and oligodendrogliomas. Acta Neuropathol 108:49-56. https://doi.org/10.1007/s00401-004-0861-Z

51. Ostrom QT, Gittleman H, Farah P, Ondracek A, Chen Y, Wolinsky Y, Stroup NE, Kruchko C, Barnholtz-Sloan JS (2013) CBTRUS statistical report: primary brain and central nervous system tumors diagnosed in the United States in 2006-2010. Neuro-Oncology 15

52. Paldino MJ, Wong TZ, Reardon DA, Friedman HS, Barboriak DP (2011) Prognostic significance of parameters derived from coregistered $18 \mathrm{~F}$-fluorodeoxyglucose $\mathrm{PET}$ and contrast-enhanced MRI in patients with high-grade glioma. Br J Radiol 84:327. https://doi.org/10.1259/bjr/48528504

53. Perry A, Wesseling P (2016) Histologic classification of gliomas, 1st ed. Handb Clin Neurol doi:https://doi.org/10.1016/B978-0-12802997-8.00005-0

54. Pichler R, Dunzinger A, Wurm G, Pichler J, Weis S, Nubaumer K, Topakian R, Aigner RM (2010) Is there a place for FET PET in the initial evaluation of brain lesions with unknown significance? Eur J Nucl Med Mol Imaging 37:1521-1528. https://doi.org/10.1007/ s00259-010-1457-6

55. Piñeros M, Sierra MS, Izarzugaza MI, Forman D (2016) Descriptive epidemiology of brain and central nervous system cancers in Central and South America. Cancer Epidemiol 44:S141S149. https://doi.org/10.1016/j.canep.2016.04.007

56. Plotkin M, Blechschmidt C, Auf G, Nyuyki F, Geworski L, Denecke T, Brenner W, Stockhammer F (2010) Comparison of F18 FET-PET with F-18 FDG-PET for biopsy planning of noncontrast-enhancing gliomas. Eur Radiol 20:2496-2502. https:// doi.org/10.1007/s00330-010-1819-2

57. Pöpperl G, Götz C, Rachinger W, Gildehaus FJ, Tonn JC, Tatsch K (2004) Value of O-(2-[18F]fluoroethyl)-L-tyrosine PET for the diagnosis of recurrent glioma. Eur J Nucl Med Mol Imaging 31: 1464-1470. https://doi.org/10.1007/s00259-004-1590-1

58. Pöpperl G, Kreth FW, Mehrkens JH, Herms J, Seelos K, Koch W, Gildehaus FJ, Kretzschmar HA, Tonn JC, Tatsch K (2007) FET PET for the evaluation of untreated gliomas: correlation of FET uptake and uptake kinetics with tumour grading. Eur J Nucl Med Mol Imaging 34:1933-1942. https://doi.org/10.1007/s00259-0070534-y

59. Price SJ (2007) The role of advanced MR imaging in understanding brain tumour pathology. Br J Neurosurg 21:562-575. https://doi. org/10.1080/02688690701700935

60. Puttick S, Bell C, Dowson N, Rose S, Fay M (2015) PET, MRI, and simultaneous PET/MRI in the development of diagnostic and therapeutic strategies for glioma. Drug Discov Today 20:306-317. https://doi.org/10.1016/j.drudis.2014.10.016
61. Rachinger W, Goetz C, Pöpperl G, Gildehaus FJ, Kreth FW, Holtmannspötter M, Herms J, Koch W, Tatsch K, Tonn JC (2005) Positron emission tomography with O-(2-[18F]flouroethyl)-L- tyrosine versus magnetic resonance imaging in the diagnosis of recurrent gliomas. Neurosurgery 57:505-511. https://doi.org/10. 1227/01.NEU.0000171642.49553.B0

62. Rahm V, Boxheimer L, Bruehlmeier M, Berberat J, Nitzsche EU, Remonda L, Roelcke U (2014) Focal changes in diffusivity on apparent diffusion coefficient MR imaging and amino acid uptake on PET do not colocalize in nonenhancing low-grade gliomas. J Nucl Med 55:546-550. https://doi.org/10.2967/jnumed.113. 130732

63. Ricci PE, Dungan DH (2001) Imaging of low- and intermediategrade gliomas. Semin Radiat Oncol 11:103-112. https://doi.org/10. 1053/srao.2001.21420

64. Roessler K, Gatterbauer B, Becherer A, Paul M, Kletter K, Prayer D, Hoeftberger R, Hainfellner J, Asenbaum S, Knosp E (2007) Surgical target selection in cerebral glioma surgery: linking methionine (MET) PET image fusion and neuronavigation. Minim Invasive Neurosurg 50:273-280. https://doi.org/10.1055/s-2007991143

65. Sanai N, Berger MS (2008) Glioma extent of resection and its impact on patient outcome. Neurosurgery 62:753-764

66. Santra A, Kumar R, Sharma P, Bal C, Kumar A, Julka PK, Malhotra A (2012) F-18 FDG PET-CT in patients with recurrent glioma: comparison with contrast enhanced MRI. Eur J Radiol 81:508513. https://doi.org/10.1016/j.ejrad.2011.01.080

67. Schwarzenberg J, Czernin J, Cloughesy TF, Ellingson BM, Pope WB, Geist C, Dahlbom M, Silverman DH, Satyamurthy N, Phelps ME, Chen W (2012) 3'-Deoxy-3'-18F-fluorothymidine PET and MRI for early survival predictions in patients with recurrent malignant glioma treated with bevacizumab. J Nucl Med 53:29-36. https://doi.org/10.2967/jnumed.111.092387

68. Shields AF, Grierson JR, Dohmen BM, Machulla HJ, Stayanoff JC, Lawhorn-Crews JM, Obradovich JE, Muzik O, Mangner TJ (1998) Imaging proliferation in vivo with [F-18]FLT and positron emission tomography. Nat Med 4:1334-1336. https://doi.org/10.1038/3337

69. Shinomiya A, Kawai N, Okada M, Miyake K, Nakamura T, Kushida Y, Haba R, Kudomi N, Yamamoto Y, Tokuda M, Tamiya T (2013) Evaluation of 3'-deoxy-3'-[18F]-fluorothymidine (18F-FLT) kinetics correlated with thymidine kinase-1 expression and cell proliferation in newly diagnosed gliomas. Eur J Nucl Med Mol Imaging 40:175-185. https://doi.org/10.1007/s00259-0122275-9

70. Singhal T, Narayanan TK, Jain V, Mukherjee J, Mantil J (2008) 11C-L-methionine positron emission tomography in the clinical management of cerebral gliomas. Mol Imaging Biol 10:1-18. https://doi.org/10.1007/s11307-007-0115-2

71. Singhal T, Narayanan TK, Jacobs MP, Bal C, Mantil JC (2012) $11 \mathrm{C}-$ Methionine PET for grading and prognostication in gliomas: a comparison study with 18F-FDG PET and contrast enhancement on MRI. J Nucl Med 53:1709-1715. https://doi.org/10.2967/ jnumed.111.102533

72. Smith JS, Chang EF, Lamborn KR, Chang SM, Prados MD, Cha S, Tihan T, Vandenberg S, McDermott MW, Berger MS (2008) Role of extent of resection in the long-term outcome of low-grade hemispheric gliomas. J Clin Oncol 26:1338-1345

73. Smits A, Baumert BG (2011) The clinical value of PET with amino acid tracers for gliomas WHO grade II. Int J Mol Imaging 2011: 372509. https://doi.org/10.1155/2011/372509

74. Stockhammer F, Plotkin M, Amthauer H, Landeghem FKH, Woiciechowsky C (2008) Correlation of F-18-fluoro-ethyl-tyrosin uptake with vascular and cell density in non-contrast-enhancing gliomas. J Neuro-Oncol 88:205-210. https://doi.org/10.1007/ s11060-008-9551-3 
75. Stupp R, Tonn JC, Brada M, Pentheroudakis G (2010) High-grade malignant glioma: ESMO clinical practice guidelines for diagnosis, treatment and follow-up. Ann Oncol 21:190-193. https://doi.org/ 10.1093/annonc/mdq187

76. Tovi M, Lilja A, Bergstrom M, Ericsson A, Bergstrom K, Hartman M (1990) Delineation of gliomas with magnetic resonance imaging using Gd-DTPA in comparison with computed tomography and positron emission tomography. Acta Radiol 31:417-429. https:// doi.org/10.1080/02841859009173067

77. Upadhyay N, Waldman AD (2011) Conventional MRI evaluation of gliomas. Br J Radiol 84:107-111. https://doi.org/10.1259/bjr/ 65711810

78. van Dellen JR, Danziger A (1978) Failure of computerized tomography to differentiate between radiation necrosis and cerebral tumour. S Afr Med J 53:171-172

79. Vézina L-G (2008) Imaging of CNS tumors in children: advances and limitations. J Child Neurol 23:1128-1135. https://doi.org/10. 1177/0883073808320753.Imaging

80. Wang X, Chen J, Zhou Q, Liu Y, Mao Q, You C, Chen N, Xiong L, Duan J, Liu L (2016) Statistical report of central nervous system tumors histologically diagnosed in the Sichuan Province of China from 2008 to 2013: a West China Glioma Center report. Ann Surg Oncol. https://doi.org/10.1245/s10434-016-5410-1

81. Weckesser M, Langen KJ, Rickert CH, Kloska S, Straeter R, Hamacher K, Kurlemann G, Wassmann H, Coenen HH, Schober O (2005) O-(2-[18F]fluorethyl)-L-tyrosine PET in the clinical evaluation of primary brain tumours. Eur J Nucl Med Mol Imaging 32: 422-429. https://doi.org/10.1007/s00259-004-1705-8

82. Wen PY, Macdonald DR, Reardon DA, Cloughesy TF, Sorensen AG, Galanis E, DeGroot J, Wick W, Gilbert MR, Lassman AB,
Tsien C, Mikkelsen T, Wong ET, Chamberlain MC, Stupp R, Lamborn KR, Vogelbaum MA, Van Den Bent MJ, Chang SM (2010) Updated response assessment criteria for high-grade gliomas: response assessment in neuro-oncology working group. J Clin Oncol 28:1963-1972. https://doi.org/10.1200/JCO.2009.26.3541

83. Wester H, Herz M, Weber W, Heiss P, Senekowitsch-Schmidtke R, Schwaiger M, Stöcklin G (1999) Synthesis and radiopharmacology of O-(2-fluoroethyl)-L-tyrosine for tumor imaging. J Nucl Med 40: 205-212

84. Yamamoto Y, Wong TZ, Turkington TG, Hawk TC, Reardon DA, Coleman RE (2006) 3'-Deoxy-3'-[F-18]fluorothymidine positron emission tomography in patients with recurrent glioblastoma multiforme: comparison with Gd-DTPA enhanced magnetic resonance imaging. Mol Imaging Biol MIB Off Publ Acad Mol Imaging 8:340-347. https://doi.org/10.1007/s11307-006-0063-2

85. Yoo MY, Paeng JC, Cheon GJ, Lee DS, Chung JK, Kim EE (2010) Kang KW (2015) prognostic value of metabolic tumor volume on 11C-methionine PET in predicting progression-free survival in high-grade glioma. Nucl Med Mol Imaging 49:291-297. https:// doi.org/10.1007/s13139-015-0362-0

86. Zhao F, Li M, Wang Z, Fu Z, Cui Y, Chen Z, Yu J (2015) ${ }^{18} \mathrm{~F}$ fluorothymidine PET-CT for resected malignant gliomas before radiotherapy: tumor extent according to proliferative activity compared with MRI. PLoS One 10:1-12. https://doi.org/10.1371/ journal.pone. 0118769

87. Zonari P, Baraldi P, Crisi G (2007) Multimodal MRI in the characterization of glial neoplasms: the combined role of single-voxel MR spectroscopy, diffusion imaging and echo-planar perfusion imaging. Neuroradiology. https://doi.org/10.1007/s00234-007-0253-x 